\title{
Study of the Nature of Non-Metallic Inclusions in Samples of Aluminum and Silicon Killed Low Carbon Steels, Collected in the \\ Refining Treatment and Continuous Casting Stages
}

\author{
José Carlos Santos Pires ${ }^{\mathrm{a} *}$, Amauri Garcia $^{\mathrm{b}}$ \\ ${ }^{a}$ Federal Center of Technological Education from Minas Gerais, UNED-Leopoldina, \\ José Perez Street, 558, 36700-000 Leopoldina - MG, Brazil \\ ${ }^{\mathrm{b}}$ State University of Campinas, Faculty of Mechanical Engineering, \\ Department of Materials Engineering, PO. Box: 6122, 13084-970 Campinas - SP, Brazil
}

Received: January 28, 2003; Revised: July 15, 2004

\begin{abstract}
The amount, distribution, size and chemical composition of non-metallic inclusions have a direct influence on steel properties. By controlling size and chemical composition of these inclusions, it is possible to get a product with good quality. The identification of the nature and the control of inclusion formation are very important for steel cleanness. The behavior of these inclusions is predictable, in some extent, by the determination of the chemical composition of nonmetallic phases that form such inclusions. With the objective of studying the chemical composition, the size and the distribution of such inclusions, samples of aluminum and silicon killed low carbon steels were collected in a national steel industry in the secondary refining and continuous casting stages. These samples were analyzed in the scanning electron microscope (SEM) coupled to an energy dispersive analysis system (EDS). From the results, it was possible to evaluate the nature of inclusions and to analyze the effectiveness of the refining process in the reduction of the number and area fraction of the inclusions. It was also possible to verify that the inclusions that remained after treatment, are less damage both to the steel properties as to the continuous casting process (clogging of the submerged valve).
\end{abstract}

Keywords: non-metallic inclusions, steel treatment, low carbon steel, scanning electron microscope (SEM/EDS), continuous-casting process

\section{Introduction}

The mechanical properties of steel components are controlled by the chemical composition and by the thermal and/ or mechanical treatment to which the steel is submitted. However, structural defects, such as non-metallic inclusions, are also responsible for the performance of this material when it is submitted to mechanical stress ${ }^{1}$.

The control of non-metallic inclusions, mainly oxides and sulfides, is closely related to the concept of clean steel. This concept must include a special demand regarding chemical composition, size, morphology, type and distribution of these inclusions, besides taking into account the low amount of harmful impurities, such as oxygen, sulfur, phosphorous, hydrogen and nitrogen ${ }^{2}$.

*e-mail: pires@ leopoldina.cefetmg.br

Article presented at the XV CBECIMAT, Natal - RN, November/2002
Considering the nature and quantity of deoxidizer used in the treatment of the steel, the presence of inclusions is unavoidable. However, the nature and quantity of such inclusions might be modified through the treatment of liquid steel in a ladle furnace ${ }^{3}$. In order to succeed in the treatment of liquid steel, a reasonable knowledge of the process is necessary. During the steel refining stage, it is possible to control the formation of non-metallic inclusions through the control of the chemical composition of the liquid steel and of the slag, the temperature and mainly through the amount of oxygen remaining in the last phase of the steel elaboration in the LD converter. By controlling these variables the steel may obtain characteristics which are adequate 
for mechanical forming, and to avoid the clogging of the submerged valves in the continuous casting, and thus optimize the action of the deoxidizer ${ }^{4,5}$.

The knowledge of the non-metallic phases in equilibrium with molten steel is very important for the project and for the control of the steel refinement phases, particularly deoxidation, desulfurization and the control of the shape of the inclusions ${ }^{6}$. During the treatment in the ladle furnace, the chemical composition of the melt is adjusted and the oxygen level is lowered. The inclusions, which are present in the killed steel are mainly formed by alumina, which is the product of the reaction between the aluminum and the oxygen dissolved in the bath. If calcium is added after deoxidation with the aluminum, the modification of the inclusions of alumina will occur simultaneously with the reactions of calcium and oxygen and, depending on the level of residual sulfur, there will be also the reaction of the latter with the calcium. The modification of the inclusions leads to the production of fluid particles which are easily separated from the metal; those which remain in the melt are small and spherical and, therefore, do not have high detrimental effect on the steel properties ${ }^{2,3}$.

In order to achieve the desired modifications in the composition of the inclusions, a precise control of the addition of calcium in the melt is necessary. Various types of inclusions can be formed as a function of the level of oxygen, sulfur and calcium. These levels are determined by the process parameters and by the type of steel. The prediction of optimal conditions for the formation of desirable inclusions requires complex thermodynamic calculation, as shown by Gaye et al. ${ }^{7}$ and other authors ${ }^{2,8-10}$. The performance of such calculations, in each particular type of steel, requires an extensive number of thermodynamic data that are not usually available, making the calculation even more difficult. On the other hand, a good practice to modify the composition of the inclusion should be associated to an efficient practice of elimination of inclusions during the refinement in the ladle furnace. Efficient elimination of inclusions depends on the nature of these inclusions, the chemical composition of the covering slag and the hydrodynamic conditions (agitation and injection of inert gas) of the melt during treatment ${ }^{3}$.

In this present work, a study of the chemical composition, the size and the distribution of non-metallic inclusions has been carried out in aluminium and silicon killed low carbon steel collected in a steel plant, during the stages of secondary refinement and continuous casting of such steel.

\section{Experimental Procedure}

\subsection{Sampling}

To characterize the evolution of the chemical composi- tion and of the population of inclusions during the refinement stages in the ladle furnace, and in the continuous casting, samples of aluminum killed SAE 1010 steel and silicon killed SAE 1005 steels have been collected in a heat on an industrial scale. The samples of SAE 1010 and SAE 1005 steels have been numbered, respectively, from 1 to 4 , and 5 to 8 . Both have been classified according to the stage and the collection time, as presented in Table 1.

\subsection{Optical and scanning electron microscope analyses}

The samples were prepared metalographically and analyzed, firstly in the optical microscope with the aid of an image analyzer, for the verification of the quantity of inclusions per unit of area. The analyzed area was of approximately $100 \mathrm{~mm}^{2}$. Afterwards these samples were analyzed in SEM/EDS to estimate the chemical composition of the inclusions.

\section{Results and Discussion}

The samples of aluminum killed SAE 1010 and silicon killed SAE 1005 steels were analyzed in SEM/EDS and the results are shown separately in Figs. 1 and 2. The inclusions consist basically of calcium silico-aluminates, with variable amounts of other oxides, such as $\mathrm{MnO}, \mathrm{MgO}$. In

Table 1. Sampling sequence of SAE 1010 and 1005 steels during the phases of the process.

\begin{tabular}{cc}
\hline Sample & $\begin{array}{c}\text { Aluminum killed SAE 1010 Steel } \\
\text { Description }\end{array}$ \\
\hline 1 & $\begin{array}{c}\text { Collected after tapping the steel from } \\
\text { the LD converter to the ladle furnace } \\
\text { (beginning of the treatment). } \\
\text { Collected in ladle furnace, after the } \\
\text { addition of aluminum (30 min of treatment). } \\
\text { Collected at the end of the treatment } \\
\text { in the ladle furnace after the } \\
\text { addition of the CaSi alloy. } \\
\text { (60 min of treatment). }\end{array}$ \\
4 & $\begin{array}{c}\text { Collected in the tundish (10 min after } \\
\text { the onset of continuous casting). }\end{array}$ \\
\hline 5 & $\begin{array}{c}\text { Silicon killed SAE 1005 Steel } \\
\text { Description }\end{array}$ \\
\hline 5 & $\begin{array}{c}\text { Collected in the ladle furnace at } \\
\text { the beginning of the treatment. } \\
\text { Collected in the ladle furnace } \\
\text { after 30 min of treatment. } \\
\text { Collected in the ladle furnace } \\
\text { at the end of the treatment. } \\
\text { Collected in the tundish (15 min } \\
\text { after the onset of continuous casting). }\end{array}$ \\
\hline
\end{tabular}



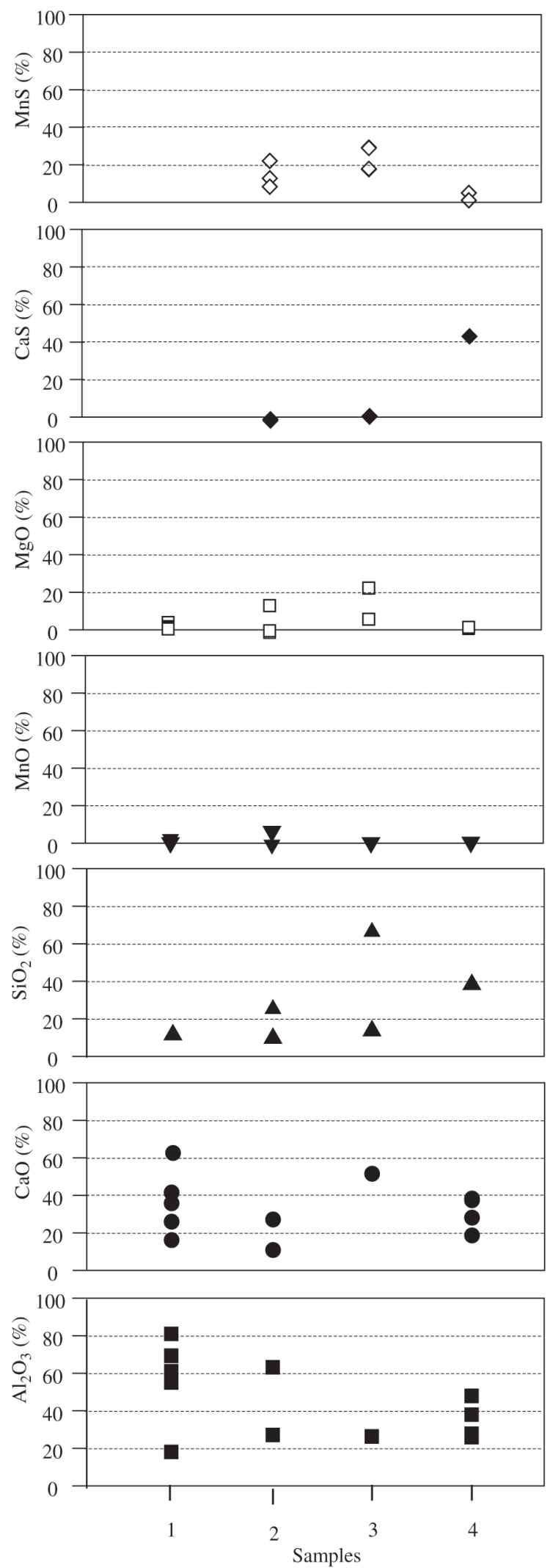

Figure 1. Evolution of the chemical composition of the inclusions in the samples of aluminum killed SAE 1010 steel. the inclusions present in the final samples of the treatment of the SAE 1010 steel, the presence of calcium and manganese sulfides could also be verified. This demonstrates that the system has evolved to the thermodynamic equilibrium between the elements present in the steel, changing the chemical composition of the inclusions. The efficiency of the treatment of the molten steel can also be verified by the variation of the alumina level in the inclusions present in the samples of both steels. It can be seen that, in the sample relative to the beginning of the treatment (Samples 1 and 5), the $\mathrm{Al}_{2} \mathrm{O}_{3}$ level reached $80 \%$ and, as the refinement treatment proceeded, this levels dropped to less than $20 \%$ in the SAE 1005 steel and to approximately 40\% in the SAE 1010 steel. This can also be seen in relation to the $\mathrm{MnO}$ in the SAE 1005 steel, where the level is initially high, about 50\%, and then decreases progressively until the end of the treatment. Another indicator of the efficient modification of the chemical composition of the inclusions is the level of calcium, whose value increased from the beginning to the end of the treatment. This indicates that there was a modification of the inclusions, which initially were predominantly of solid alumina at the elaboration temperature of the steel, becoming then composed of calcium aluminate, which is liquid at $1600{ }^{\circ} \mathrm{C}$, at the end of the treatment.

The great heterogeneity of the composition of the inclusions observed at the beginning of the treatment in the ladle furnace can be explained by considering the formation of a high saturation zone during the tapping of the steel from the LD converter to the ladle furnace. During this operation, alloying elements and deoxidizers are dissolved in the melt, creating a zone of high concentration of deoxidizing elements in the proximity of the dissolved particles. These elements will react with the dissolved oxygen, forming en-

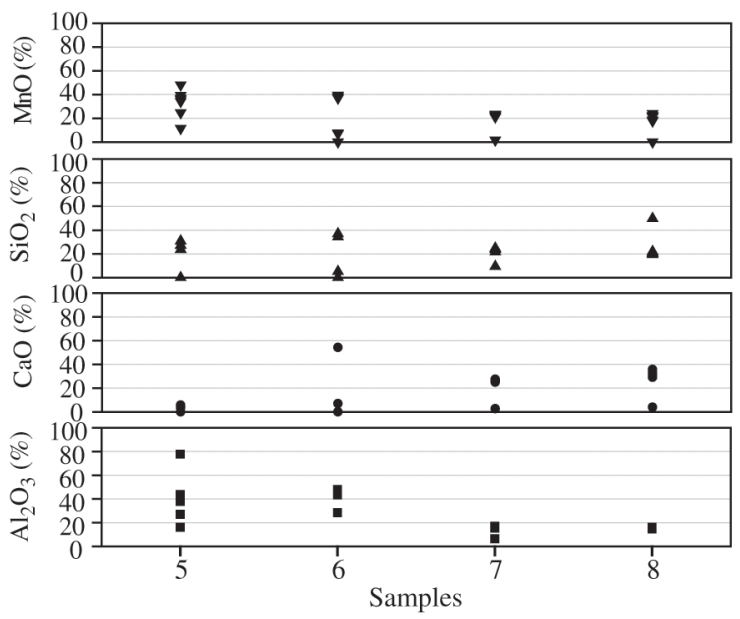

Figure 2. Evolution of the chemical composition of the inclusions in the samples of silicon killed SAE 1005 steel. 
dogenous inclusions with high levels of $\mathrm{SiO}_{2}$ and $\mathrm{Al}_{2} \mathrm{O}_{3}$, which will join the particles of slag formed during the tapping. In this second reaction, big exogenous inclusions of aluminum will be formed depending on the quantities of silicon and aluminum dissolved and also on the $\mathrm{Al}_{2} \mathrm{O}_{3} / \mathrm{CaO}$ relation in the slag. With the continuation of the treatment in the ladle furnace, these big inclusions are eliminated progressively, as can be inferred from the results presented in Figs. 3 and 4.

However long the treatment in the ladle furnace might prove to be, inclusions smaller than $25 \mu \mathrm{m}$ will always be present in the bulk of molten steel and will remain in the microstructure after solidification. Therefore, it is neces-

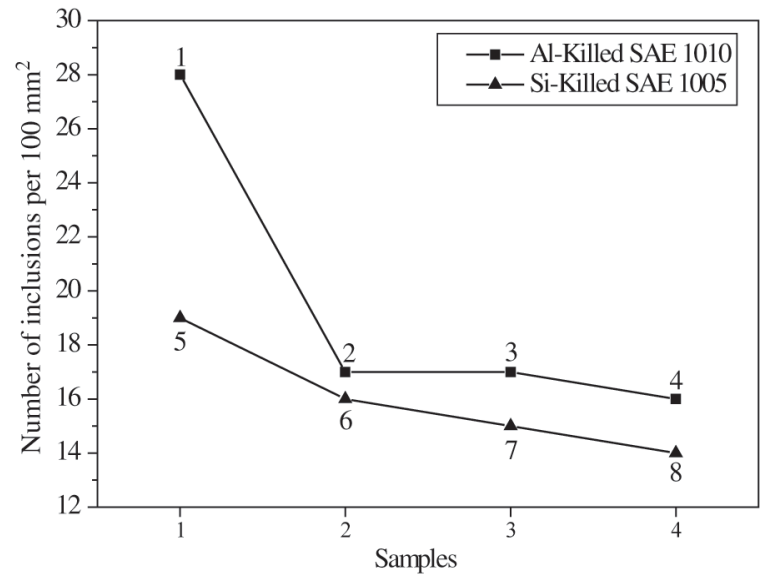

Figure 3. Variation of the number of inclusions per $100 \mathrm{~mm}^{2}$ of area in the samples of the SAE 1010 and 1005 steels.

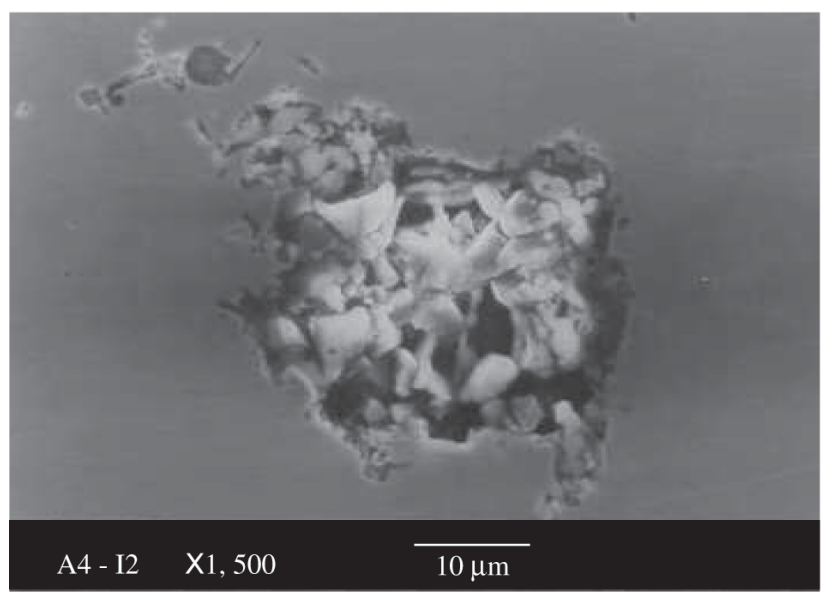

(a)

(Si 0.25; Al 95.50; Ca 0.61; Mn 3.39) sary to control the composition of these inclusions so that they will be deformable during the subsequent process of plastic deformation of the steel.

Figure 5 presents photographs of inclusions analyzed in SEM/EDS. The inclusion in Fig. 5a was obtained in Sample 2 of aluminum killed SAE 1010 steel, whereas the inclusion in Fig. 5b was detected in the Sample 6 of silicon killed SAE 1005 steel. The chemical composition of these inclusions, in weight percent, is also presented in Fig. 5.

\section{Conclusions}

The results presented allow the following to be concluded:

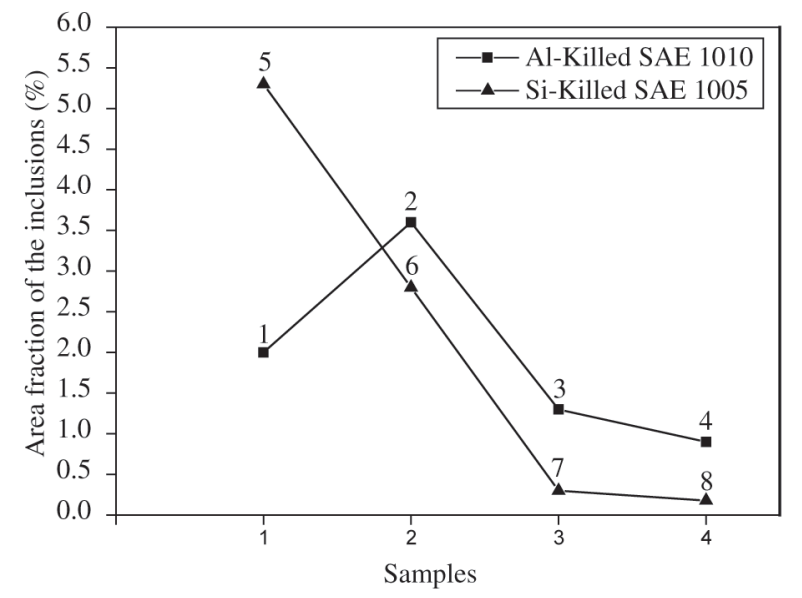

Figure 4. Area fraction of the inclusions in the samples of the SAE 1010 and 1005 steels.

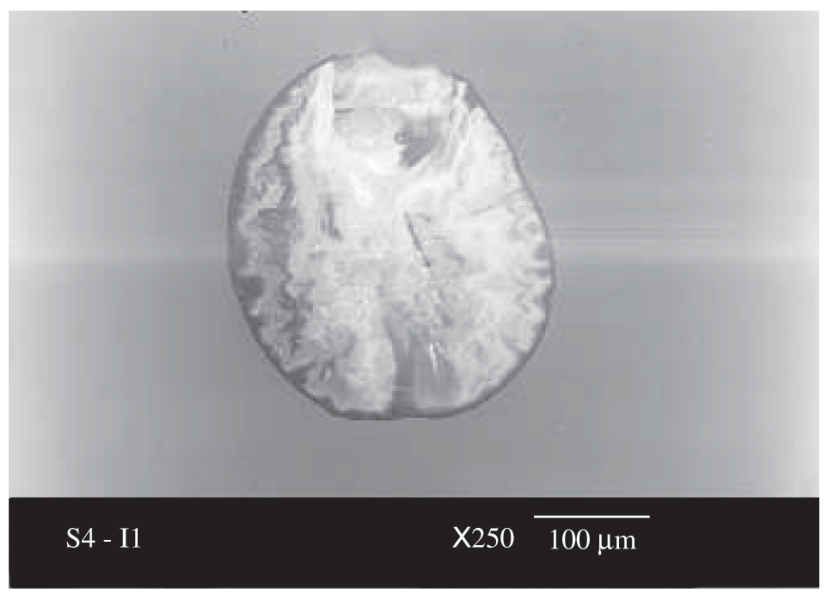

(b)

(Si 42.08; Al 33.32; Ca 16.08; Mn 7.98)

Figure 5. a) Inclusion from the sample of aluminum killed SAE 1010 steel; b) inclusion from the sample of silicon killed SAE 1005 steel. 
- It was possible to know better the nature of the nonmetallic inclusions that are formed in aluminum killed SAE 1010 steel and in the silicon killed SAE 1005 steel. Based on this knowledge, steps can be taken in order to try to minimize their formation through adequate refinement practice.

- It was verified that the treatment of both steels in the ladle furnace was adequate since it managed to progressively eliminate the big inclusions, fixing them in the top slag.

- Another pertinent observation is in relation to the modification of the chemical composition of the inclusions present in both steels. At the beginning of the treatment, these inclusions were practically of pure alumina, which are solid at $1600{ }^{\circ} \mathrm{C}$, whereas at the end of the treatment, after the addition of $\mathrm{Ca}$ based alloys, the composition of the inclusions changed to calcium aluminate.

\section{Acknowledgements}

The authors wish to thanks FAPESP (The Scientific Research Foundation of State of the São Paulo, Brazil), and CNPq (The Brazilian Research Council) for financial support for the research. We would also like to thank the Belgo Mineira S.A. for supplying the steel samples and the technicians of the material characterization laboratory of DEMA/ FEM/UNICAMP for their support during the analysis of the samples in SEM/EDS.

\section{References}

1. Gagné, M.; Thibault, E. Can. Metall. Quarterly, v. 38, n. 5, p. 311-321, 1999.

2. Holappa, L.E.K.; Helle, A.S. J. Mat. Proc. Technology, v. 53, p. 177-186, 1995.

3. Herrera-Trejo, M.; Castro, M.R.; Méndez, J.N.; Solís, H.T.; Tena, J.M.; Guzmán, E. Scand. J. Metallurgy, v. 27, p. 233-239, 1998.

4. Oertel, L.C.; Costa e Silva, A.L.V. Proceedings of the XXVIII Steelmaking seminar - Brazilian Materials Association (ABM), Campinas, SP, Brazil, May, 1997.

5. Fernandes Neto, M.; Cheung, N.; Garcia, A. Proceedings of the XXXI Steelmaking seminar - Brazilian Materials Association (ABM), Vitória, ES, Brazil, May, 2000.

6. Oertel, L.C.; Costa e Silva, A.L.V. Calphad, v. 23, n. 34 p. 379-391, 1999.

7. Gaye, H.; Gatellier, C.; Nadif, M.; Riboud, P.V. Saleid, J.; Faral, M. Rev. Métallurgie-CIT, nov., p. 759-771, 1987.

8. Larsen, K.; Fruehan, R.J. ISS Transactions, v. 12, p. 125-132, 1991.

9. Fernandes, M.; Cheung, N.; Garcia, A. Mat. Characterization, v. 48, p. 255-261, 2002.

10. Fenandes Neto, M.; Cheung, N.; Pires, J.C.S.; Garcia, A. Acta Microscopica Supplement A, XVIII Congress of the Brazilian Society for Microscopy and Microanalysis, p. 267-268, 2001. 